\title{
Paidéia consagra-se como revista A1 no Qualis Periódico CAPES
}

Este fascículo marca uma série de conquistas notáveis, que corroboram a ascensão definitiva da Paidéia no panteão das publicações científicas em Psicologia. A divulgação, pela CAPES, do Qualis Periódico representou uma conquista histórica para a revista e, por extensão, para a Faculdade de Filosofia, Ciências e Letras de Ribeirão Preto da Universidade de São Paulo, solo institucional onde está instalada a Paidéia. O Qualis designa um conjunto de procedimentos utilizados pela CAPES para estratificação da qualidade da produção intelectual dos programas de pósgraduação no Brasil. O resultado é uma lista que contempla a classificação dos periódicos utilizados pelos programas para disseminar a produção científica. Entre os periódicos avaliados na área da Psicologia, a Paidéia foi classificada como A1. Foi um extraordinário salto de duas posições no gradiente de classificação, considerando que a revista se encontrava no estrato B1.

Concomitantemente, no início de 2012 a Paidéia foi uma das duas revistas nacionais da área da Psicologia escolhidas para participarem do Programa de Apoio delineado pela CAPES para subsidiar periódicos que almejam consolidar sua internacionalização nos próximos anos. Essa indicação foi patrocinada pela Comissão de Avaliação Qualis Periódicos e pela Coordenação de Área de Avaliação (Psicologia) da CAPES. A honrosa distinção recebida, baseada no reconhecimento dos méritos do projeto editorial e do Plano de Ação encaminhado pela revista, implica uma contrapartida de nossa parte, que se traduz, objetivamente, no cumprimento de algumas metas pactuadas. Nessa direção, a Paidéia selou seu compromisso com metas de qualidade a serem alcançadas nos próximos anos, acompanhadas das respectivas estratégias a serem adotadas para sua consecução. Assim, estamos dando início à implantação de um Plano de Ação arrojado e audacioso, visando a aumentar a visibilidade internacional dos artigos publicados.

As metas delineadas junto à CAPES almejam qualificar a revista para servir, nos próximos anos, de referência internacional na área da Psicologia. Desde o final de 2011 estamos vivenciando um processo de mudanças substanciais, como a reformulação da linha editorial, implantação da submissão eletrônica dos manuscritos - via Submission, ampliação das bases indexadoras e, especialmente, a disponibilização dos artigos na íntegra em língua inglesa. $\mathrm{O}$ cumprimento desse requisito passou a ser condição para publicação do artigo e, por essa razão, os autores foram notificados dessa exigência.

Um passo importante para a implementação da versão completa na língua inglesa consistiu em credenciar tradutores qualificados, constituindo um Comitê de Tradutores
Credenciados, seguindo a trilha aberta por revistas de outras áreas do conhecimento que já haviam adotado tal procedimento. A Paidéia já veiculava os resumos em português, inglês e espanhol, o que sempre se constituiu em um diferencial em relação a outras revistas da área da Psicologia que, tradicionalmente, só exigem o resumo em português e inglês. A inclusão do resumo em espanhol amplia a visibilidade dos artigos nos países da América Latina. Agora a Paidéia inova mais uma vez ao implantar a publicação dos artigos em inglês. Na área da Psicologia, estamos sendo pioneiros nessa exigência.

Por sua vez, a implantação do Submission - uma ferramenta disponibilizada pela SciELO, permitirá um melhor gerenciamento do fluxo de informações, contribuindo para reduzir o tempo médio de tramitação dos manuscritos. A Comissão Editorial considera que a adoção desse recurso é condição sine qua non para agilizar o fluxo de avaliação, permitindo cumprir os prazos exigidos pela ciência contemporânea, cada vez mais exigente em relação ao tempo decorrido entre a submissão do manuscrito e sua aprovação e publicação. As diversas etapas operacionais necessárias para a implementação do Submission foram concluídas, como o cadastramento de assessores $a d$ hoc, atualização, adaptação e inserção de normas no sistema e na página da SciELO nos idiomas português, inglês e espanhol, informações sobre a Comissão Editorial, reformulação do documento de submissão pelos autores e do formulário de avaliação pelos pareceristas, criação dos "itens de verificação", entre outros itens. Foi dada ampla publicidade à comunidade científica acerca dessa mudança, informando que a Paidéia estaria migrando para o sistema Submission disponibilizado pela plataforma SciELO.

O período para submissões on line continua aberto o ano todo. Mesmo na etapa de transição que vivenciamos, em nenhum momento foi suspensa a submissão de novos manuscritos. Com a entrada em vigor do processo de submissão on line, esperamos também consolidar a meta de facilitar a comunicação entre os autores e a revista, visando a aprimorar o processo de seleção e divulgação de artigos de elevada qualidade científica.

Outra notícia auspiciosa que merece ser comemorada é que acabamos de disponibilizar on line o acervo completo da revista na biblioteca SciELO (http://www.scielo.br/paideia). Em agosto de 2011, a Paidéia completou 20 anos de existência. Desde sua fundação, em agosto de 1991, foram publicados 51 fascículos, do volume 1 ao 22. Agora o acervo completo encontra-se totalmente disponibilizado, em acesso livre e gratuito assegurado pela Coleção SciELO. Essa façanha contou com o apoio decisivo da Universidade de São 
Paulo e do Conselho Nacional de Desenvolvimento Científico e Tecnológico - CNPq.

Paralelamente, temos desenvolvido um trabalho de contínuo aprimoramento do processo editorial, a partir da profissionalização da gestão editorial e de investimentos na melhoria da infraestrutura administrativa e dos recursos humanos. Os recursos financeiros, imprescindíveis para dar sustentabilidade às propostas em curso, até o momento têm sido garantidos por três fontes de financiamento: Programa de Apoio às Publicações Científicas Periódicas da USP por intermédio de sua Comissão de Credenciamento, CNPq e Programa de Pós-graduação em Psicologia da FFCLRPUSP.

Os artigos enfeixados no presente volume refletem o contexto de transformação e crescimento que tem animado o processo editorial. O artigo Escala Multidimensional de Atitudes face a Lésbicas e a Gays: Construção e Validação Preliminar, da autoria de Jorge Gato, Anne Marie Fontaine, e Nuno Santos Carneiro, da Universidade do Porto, Portugal, apresenta dados a respeito da criação e validação de uma escala multidimensional para escrutínio da atitude face a lésbicas e a gays. As análises fatoriais exploratórias apontam para três dimensões atitudinais negativas que compõe o instrumento, duas de seio mais tradicional (Rejeição da proximidade e Homopatologização) e outra de aspecto moderno (Heterossexismo moderno), além de uma atitude positiva (Suporte). Os autores afirmam que a escala em questão revelou boas características psicométricas e que compete aos objetivos mensurados.

Na sequência, o artigo Estudo Nacional dos Atributos Psicométricos da Escala Triangular do Amor de Sternberg, da autoria de Vicente Cassepp-Borges, da Universidade Federal da Grande Dourados, e Luiz Pasquali, da Universidade de Brasília, investigou os atributos psicométricos desta escala no âmbito brasileiro. Os resultados sugerem que o instrumento apresenta a estrutura de três fatores prevista pela teoria que o fundamenta, bem como elevado nível de precisão. A Teoria de Resposta ao Item mostrou que a escala contém itens altamente discriminativos.

Em Metas de Socialização em Diferentes Contextos, artigo de autoria nacional e internacional, Eulina da Rocha Lordelo e Akemy Brandão Mochizuki, da Universidade Federal da Bahia, e Monika Roethle, da University of Stavanger, Stavanger, Noruega, compararam metas de socialização de populações de diferentes contextos, em amostra de 76 mães brasileiras e 52 norueguesas. As pesquisadoras sugerem que, devido a diferenças culturais e socioeconômicas, as maiores diferenças constatadas relacionam-se aos valores individualismo/coletivismo, e são congruentes com as diferenças ecológicas entre os dois contextos.

Em Perspectiva Experiencial da Conversa Interna no Contexto de Resolução de Problemas, assinado por Amanda da Costa DaSilveira e William Barbosa Gomes, da Universidade Federal do Rio Grande do Sul, investiga-se o fenômeno da conversa interna, calcado em uma leitura fenomenológica, em duas condições diferentes, a partir de amostra de estudantes universitários submetidos à aplicação de instrumentos específicos. A discussão dos dados destaca a tríade estrutural de uma voz (eu) que fala a uma terceira parte (você) sobre um objeto (mim), a intencionalidade bidimensional entre a tarefa e o self e, por fim, as interferências da ruminação no desempenho no teste de Raven.

No artigo A Qualidade da Motivação em Estudantes do Ensino Fundamental, Sueli Édi Rufini, José Aloyseo Bzuneck e Katya Luciane de Oliveira, da Universidade Estadual de Londrina, investigaram a qualidade motivacional de estudantes do ensino fundamental por meio da aplicação de instrumento de autorrelato. Os achados evidenciam que a desmotivação e a motivação controlada aumentaram conforme a progressão nas séries, ao contrário da motivação autônoma, que diminuiu. Ao final, os autores discutem as implicações educacionais dos resultados. Face ao temerário déficit na qualidade do ensino básico vigente no Brasil, este estudo se reveste de suma importância na medida em que contribui para fornecer subsídios para implantar programas multidisciplinares com vistas a incrementar o nível de ensino.

O estudo Evidências Desfavoráveis para Avaliação da Personalidade com um Instrumento de 10 Itens, da autoria de Lucas de Francisco Carvalho, da Universidade Presbiteriana Mackenzie, Maiana Farias Oliveira Nunes, da Universidade Federal do Rio Grande do Sul, Ricardo Primi, da Universidade São Francisco, e Carlos Henrique Sancineto da Silva Nunes, da Universidade Federal de Santa Catarina, investigou a estrutura interna, a precisão e as diferenças de média por sexo e idade, com base na aplicação da escala TenItem Personality Inventory (TIPI) para avaliação dos Cinco Grandes Fatores de Personalidade, em uma amostra de 404 estudantes do ensino médio. Os resultados obtidos apontam que foi possível recuperar três do cinco fatores originais, que versam sobre conteúdos de desejabilidade social, problemas de ajustamento e estabilidade emocional.

Na sequência, Mudança em Pacientes de Clínica-escola: Avaliação de Resultados e Processos, Giovanna Corte Honda e Elisa Medici Pizão Yoshida, da Pontifícia Universidade Católica de Campinas, avaliaram indicadores de mudanças em pacientes atendidos em clínica-escola a fim de investigar fatores que influenciaram os resultados das psicoterapias. $\mathrm{O}$ estudo pautou-se na aplicação de roteiros semiestruturados de entrevistas, além de instrumentos para avaliar eficácia adaptativa, estágio de mudança e sintomas psicopatológicos. Embora se trate de estudo retrospectivo, as autoras sugerem que a aliança terapêutica positiva e a disposição do paciente como agente da própria mudança parecem ser relevantes nos 
resultados das psicoterapias, e apontam para a importância de pesquisas longitudinais para perscrutar os processos psicoterapêuticos desde o início.

Em Avaliação do Programa Informatizado de Leitura Estratégica para Estudantes do Ensino Fundamental, Maria Cristina Rodrigues Azevedo Joly e Nayane Martoni Piovezan, da Universidade São Francisco, apresentam os resultados da apreciação de uma ferramenta que se propõe a melhorar os níveis de compreensão de leitura de alunos do ensino fundamental. Os participantes foram 58 alunos de $5^{\text {a }}$ a $8^{\mathrm{a}}$ séries, com idade de 12,52 anos. Apesar da universalização do acesso ao ensino fundamental no país, as estatísticas evidenciam que muitos estudantes apresentam déficits educacionais que não podem ser subestimados. Estudos desta natureza são importantes no sentido de constatar indicadores factuais, ao mesmo tempo em que apresentam estratégias para modificar alguns de seus aspectos.

Na sequência, no artigo Comunicação e Envolvimento: Possibilidades de Interconexões entre Família-escola?, Keila Hellen Barbato Marcondes e Silvia Regina Ricco Lucato Sigolo, da Universidade Estadual Paulista, campus Araraquara-SP, analisam as relações estabelecidas entre a escola e a família de crianças com baixo rendimento escolar em instituições que adotam o regime de progressão continuada, com base na perspectiva bioecológica de Bronfenbrenner. Foram entrevistadas seis crianças, seus respectivos responsáveis e professoras. As autoras destacam que a comunicação entre as duas instituições merece ser aprimorada, diante da constatação de que se tem mantido um caráter assimétrico e enviesado por preconceitos.

No artigo Personalidade Paterna como Fator Prognóstico no Tratamento da Tendência Antissocial, Valéria Barbieri e Jamila de Godoy Pavelqueires, da Universidade de São Paulo, Ribeirão Preto-SP, discutem as características de personalidade de pais de crianças com tendência antissocial, avaliadas via psicodiagnóstico interventivo, e sua relação com os resultados terapêuticos dos filhos, sendo os pais submetidos ao Teste de Rorschach. O seguimento (follow-up) dos casos indicou a ocorrência de cinco sucessos e dois fracassos terapêuticos. Os dados evidenciam a importância da inclusão de informações sobre a personalidade paterna na indicação terapêutica de crianças e no estabelecimento do prognóstico.

No artigo Parentalidade e o Desenvolvimento Psíquico na Criança, Cássio Marcelo Batista Veludo e Terezinha de Camargo Viana, da Universidade de Brasília, analisam a noção de parentalidade a partir do arcabouço teórico da psicanálise. Os autores postulam que a parentalidade, ao infiltrar-se no narcisismo dos próprios pais, pode compor-se como fonte de tensão que frutifica determinadas reações que o eu da criança desenvolve e que contribuem para o maior ou menor sucesso na passagem do princípio de prazer para o princípio de realidade.
Abrindo a seção dedicada às revisões da literatura, o artigo Impacto Psicossocial do Câncer Pediátrico para Pais: Revisão da Literatura, Marina Kohlsdorf e Áderson Luiz Costa Junior, da Universidade de Brasília, escrutinam a literatura a respeito das vicissitudes familiares do diagnóstico do câncer infantil, mediante buscas em importantes bases de dados. Os autores destacam temas sugestivos para pesquisas, que podem subsidiar intervenções psicossociais eficientes a fim de minorar os custos psicossociais vividos por cuidadores pediátricos ao longo do tratamento.

Dando sequência ao intrincado debate sobre parentalidade e paternidade, Paternidade no Contexto das Necessidades Especiais: Revisão Sistemática da Literatura, da autoria de Camila Guedes Henn e Maúcha Sifuentes, da Universidade Federal do Rio Grande do Sul, recupera as pesquisas relacionadas à temática em questão de acordo com revisão de publicações nacionais e internacionais. De acordo com as autoras, houve incremento quantitativo das pesquisas na área, embora ainda seja pequeno o número de publicações a respeito, visto que o pai é abordado nos estudos sobre portadores de necessidades especiais, no entanto, não ocupa papel central nessas investigações.

Encerrando o fascículo, a resenha A História de uma Pioneira da Psicanálise Brasileira: Um Estudo Historiográfico sobre Virgínia Bicudo, de Iúri Yrving Müller da Silva, da Universidade Estadual Paulista, campus de Assis-SP, apresenta o livro Virgínia Bicudo: A trajetória de uma psicanalista brasileira, de Jorge Luís Ferreira Abrão, professor da Universidade Estadual Paulista, campus de Assis-SP.

Em nome da Comissão Editorial, compartilho os louros das conquistas com todos aqueles que, nesse percurso de duas décadas, contribuíram para consolidar a Paidéia no patamar de excelência em que hoje se encontra. Não restam dúvidas de que este é um momento de júbilo, especialmente para o Departamento de Psicologia da Faculdade de Filosofia, Ciências e Letras de Ribeirão Preto e para o Programa de Pós-graduação em Psicologia. Por outro lado, devemos ter serenidade para usufruirmos, com responsabilidade e a necessária humildade, desse estado de maioridade plena que nos foi outorgado pela instituição que propõe as políticas científicas no Brasil. É preciso comemorar a consagração da Paidéia com os pés plantados no chão, conscientes de que agora, mais do que nunca, é hora de unirmos nossas forças e arregaçarmos as mangas para cumprirmos a árdua agenda de trabalho que temos pela frente.

Fica aqui consignado nosso reconhecimento ao competente trabalho da Comissão Qualis Periódico da Psicologia, presidida pelo Prof. Dr. Antonio Virgílio B. Bastos, coordenador da Área de Psicologia da CAPES. Recomendamos a leitura do relatório que subsidiou o processo de avaliação (Bastos et al., 2012). Trata-se de um documento de refinada tessitura, fartamente fundamentado em dados. 
Mais do que tempo de celebrar efusivamente as benesses, é tempo de trabalhar arduamente para consolidar as conquistas.

Manoel Antônio dos Santos

Editor

\section{Referência}

Bastos, A. V. B. et al. (2012). Área de Psicologia-Atualização do webqualis da área (Comunicado No. 001/012). Recuperado de Coordenação de Aperfeiçoamento de Pessoal de Nível Superior, Diretoria de Avaliação, em 11 abril 2012, de http:/www.capes.gov.br/images/stories/ download/avaliacao/Qualis___Psicologia.pdf 